Volume 8. No. 6, June 2020

International Journal of Emerging Trends in Engineering Research

Available Online at http://www.warse.org/IJETER/static/pdf/file/ijeter27862020.pdf https://doi.org/10.30534/ijeter/2020/27862020

\title{
AMHS: Aedes Mosquito Home System with pyriproxyfen based formulation
}

\author{
Mustafa Man ${ }^{1}$, Wan Aezwani Wan Abu Bakar ${ }^{2 *}$, Lee Yean Wang ${ }^{3}$, Lim Chee $\mathrm{Hwa}^{4}$ \\ ${ }^{1}$ Faculty of Ocean Engineering and Technology, Universiti Malaysia Terengganu, 21030 Kuala Terengganu \\ Terengganu, Malaysia.mustafaman@umt.edu.my \\ ${ }^{2}$ Faculty of Informatic and Computing, Universiti Sultan Zainal Abidin, Besut Campus, 22200 Besut, \\ Terengganu. Malaysia.wanaezwani@unisza.edu.my \\ ${ }^{3}$ DrMos Health Care Sdn. Bhd., $1{ }^{\text {st }}$ Floor, No 28, Jalan 4 Aman Square, Sungai Petani, 08000 Kedah, \\ Malaysia. leeyeanwang@drmoshealthcare.com \\ ${ }^{4}$ One Team Network, 1-1B, Block 6, Jalan Pahat 15/H, Section 15, 40200 Shah Alam, Selangor. \\ limcheehwa@gmail.com
}

\begin{abstract}
Questionnaire studies were carried out against local residents of Taman Ria Jaya, Kedah, Malaysia after AedesTech Mosquito Home System was installed in the area for a period of one year. A total of 119 local residents were participated in this questionnaire study, while 117 of them voluntary to answer the questionnaire. The study found that all the participants were aware that Aedes mosquito is the dengue disease vector. As high as $86.21 \%$ of the resident feel AMHS is a good system and able to reduce the mosquito population, while $13.79 \%$ feel the mosquito population still remain the same, and $0.85 \%$ not sure about the effectiveness of the AMHS. There is $91.38 \%$ of the residents agreed that the AMHS mosquito trap help in dengue control in this area. All of the residents agreed to allow authority or industry to install AMHS in their area if this program continues. Most of the residents agreed to use AMHS (Mosquito Trap) (89.66\%), follow by Fogging (30.17\%), breeding Site reduction (20.69\%), and lastly larviciding (15.52\%) as for the dengue disease control measures. There are $89.80 \%$ of the comments were positive and encouraging towards the AMHS, such as residents feel good and satisfied (15 comments or 30.61\%), AMHS help to reduce mosquito population (22 comments or $44.90 \%$ ), and AMHS is very effective ( 2 comments or $4.08 \%$ ). However, we also found some negative comments against AMHS. It is up to $6.12 \%$ comments are negative against AMHS. The negative nevertheless were AMHS is the same, mosquito population do not reduce (3 comments or $6.12 \%$ ), and other comments $(4.08 \%)$, such as due to Pet, do not encourage fogging activity and can only accept water-based fogging.
\end{abstract}

Key words: Aedes mosquito, AedesTech Mosquito Home System, pyriproxyfen, questionnaire, dengue vectors

\section{INTRODUCTION}

Aedes aegypti (yellow fever mosquito and sneaky biter) and Aedes albopictus (Asian tiger mosquito and aggressive biter) are potential arboviral vectors leading to high human fatality worldwide (refer to Table 1 for differences). Those species are main and secondary vectors for dengue fever. Efforts in [1] were made to differentiate the eggs of Aedes aegypti (AEG) and Aedes albopictus (ALB) morphologically and morphometrically using scanning electron microscopy (SEM). Between the two species, AEG is the main contributor [2] to those diseases such as dengue, chikungunya, yellow fever, or Zika. AEG known for its domestic endophilic mosquito in decades and inevitably propagating [3].

Table 1: Aedes Aegypti (AEG) Vs. Aedes Albopictus (ALB)

\begin{tabular}{|c|c|c|}
\hline Feature & $\begin{array}{c}\text { AEDES AEGYPTI } \\
\text { (AEG) }\end{array}$ & $\begin{array}{l}\text { AEDES ALBOPICTUS } \\
\text { (ALB) }\end{array}$ \\
\hline Other name & - Yellow fever & - Asian tiger \\
\hline $\begin{array}{l}\text { Dorsal } \\
\text { Pattern }\end{array}$ & $\begin{array}{ll}\begin{array}{l}\text { bright } \\
\text { lyre-shaped }\end{array} & \text { silver } \\
\end{array}$ & - bright silver lyre-shaped \\
\hline $\begin{array}{l}\text { Dorsal } \\
\text { Stripe and } \\
\text { Legs }\end{array}$ & $\begin{array}{l}\text { - single longitudinal } \\
\text { silvery dorsal stripe } \\
\text { and white banded } \\
\text { legs }\end{array}$ & $\begin{array}{l}\text { - single longitudinal } \\
\text { silvery dorsal stripe } \\
\text { and white banded legs }\end{array}$ \\
\hline Locality & $\begin{array}{l}\text { - Occupy in urban areas } \\
\text { with/without }\end{array}$ & $\begin{array}{l}\text { - Occupy in urban areas } \\
\text { with/without }\end{array}$ \\
\hline Vegetation & - yes & - yes \\
\hline $\begin{array}{l}\text { Associated } \\
\text { to thickets } \\
\text { and arboreal } \\
\text { vegetation }\end{array}$ & - yes & - yes \\
\hline Habit & $\begin{array}{l}\text { - indoors/outdoors } \\
\text { biting, resting, and } \\
\text { laying eggs }\end{array}$ & $\begin{array}{l}\text { - indoors/outdoors biting, } \\
\text { resting, and laying } \\
\text { eggs }\end{array}$ \\
\hline
\end{tabular}


Scientifically, four (4) life stages of Aedes mosquitoes are egg, larva, pupa and adult. Mosquitoes live and reproduce especially around high population area. Figure 1 shows the four (4) life cycle starting from egg to an adult that resume in 8 to 10 days whereas in 2 to 3 days only for pupae to turn into adult mosquitoes. The mature adult mosquitoes will lay eggs in five (5) or more breeding sites and they will ensure the survival of their eggs to the adult mosquito level.

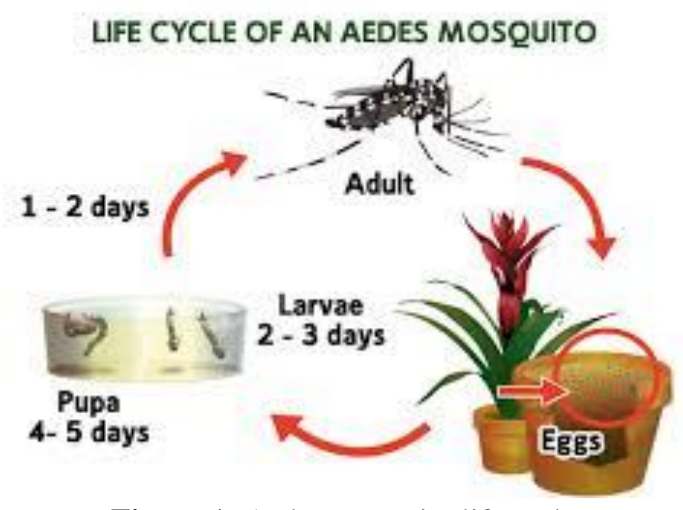

Figure 1: Aedes Mosquito life cycle

Dengue hemorrhagic fever (DHF) or dengue fever (DF) that is caused by Aedes aegypti and Aedes albopictus constantly increase in pattern while signaling high mortality [4] - [5]. Vector control is one of the most effective approaches in combating DHF/DF. Because of the transmission [6] - [7], it is critical to initiate vector control starting from the immature stages. Reports indicate there's a resistance of mosquitoes to insecticides even though a chemical control of adult mosquitoes provides quick knockdown/mortality. Resistance of Aedes aegypti to organophosphate [8] - [9], permethrin [10], DDT and dieldrin [11] have been well documented.

Research indicates that Pyriproxyfen (PPF), an insect growth regulator (IGR) is effective cure against all vectors such as AEG [11] - [12], Culex [13] - [14] and Anopheles [15]). In contrast, other PPF products i.e. pyriproxyfen $0.5 \% \mathrm{w} / \mathrm{w}$ called as Sumilarv 0.5 fail to kill larvae instead performs a residual activity extension that inhibits adult emergence. Auto-dissemination concept using the "lure and kill" towards adult mosquitoes is another alternative in combating the issues. Research proposes several approaches to exploit Edhazardia aedis (Microsporidia) and the entomopathogenic fungus (Metarhizium anisopliae) as agents for controlling Aedes aegypti [16]. It demonstrates that those gravid female Aedes aegypti that have been contaminated with PPF were able to transfer lethal concentrations to larval habitats. This was done through skip oviposition behavior of gravid Aedes aegypti females, which laid their eggs throughout several containers [17].
AedesTech Mosquito Home System (AMHS) is a commercial Aedes mosquito trap that uses the "lure and kill" concept. AMHS is an auto-dissemination mosquitoes trap that is packaged with the pyriproxyfen, to contaminate gravid female mosquitoes during oviposition, enabling dissemination of the chemical to other Aedes' oviposition sites. The use of pyriproxyfen also prevent the immature mosquito from hatching to adult. Automatic dissemination is a 'pull' and 'push' technology which allows mosquito control professionals to treat larval habitats in a timely and economical fashion [17]. Aedes mosquitoes will self-inoculate themselves with an active compound and disseminate the material to other breeding sites.

This research study is to attain the satisfaction and acceptance level of local residents prior to our AedesTech Mosquito Home System (AMHS) installation in dedicated area for a period of one year.

\section{MATERIALS AND METHODS}

AMHS [18] - [19] as shown in Figure 2(a), that is a trap device designed to attract Aedes mosquitoes and target container-breeding mosquitoes by providing an attractive smell of water source (that formulated with pyriproxyfen) as shown in Figure 2(b) for oviposition (breeding) sites. Females attracted to the device are killed and reproduction is eliminated. The concept of "Lure \& Kill Technology" purposely to control $\&$ eliminate mosquitoes during all life cycle stages i.e. from eggs, larvae, pupae or adults, to reduce the overall mosquito population. We have set up 400 units of AMHS in September 2018 until August 2018 for a year period. The installation focus at surrounding area of the trial site in each specific location such as outside the residential house, at the fence, gate or at the front door. The pheromone or Insecticide Growth Regulator (IGR) in each AMHS is refilled based on monthly basis. This formulation will pollute the new reproductive site of female Aedes, and remove the formulas and kill the entire larvae in the breeding ground.

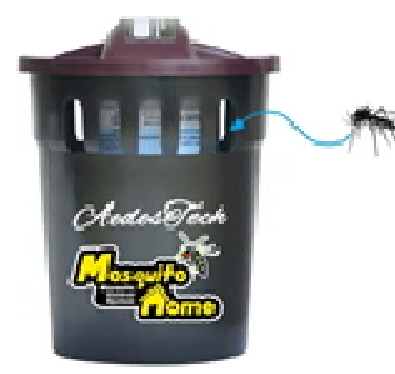

Figure 2(a): Mosquito Home System (MHS) or Aedes Trap

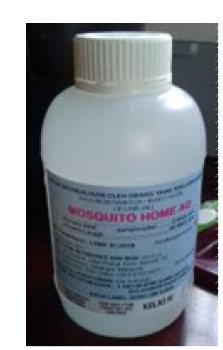

Figure 2(b): IGR or attractant refill 
The AMHS is designed with green technology and its size is sleek enough for an outdoor or inner sites or location. The interior skeleton of AMHS is depicted in Figure 3. The device is measured in $19.7 \mathrm{~cm}$ (height) by $14.6 \mathrm{~cm}$ (width) that consists of $500 \mathrm{ml}$ of $40 \mathrm{ppm}$ pyriproxyfen (PPF) treated water as shown in Figure 4. The egg collection tissue will be placed in inner wall of MHS.

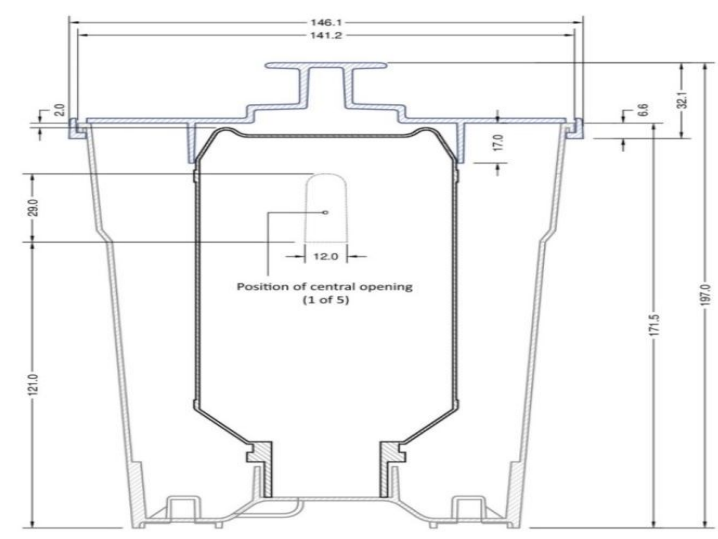

Figure 3: Interior skeleton of AMHS
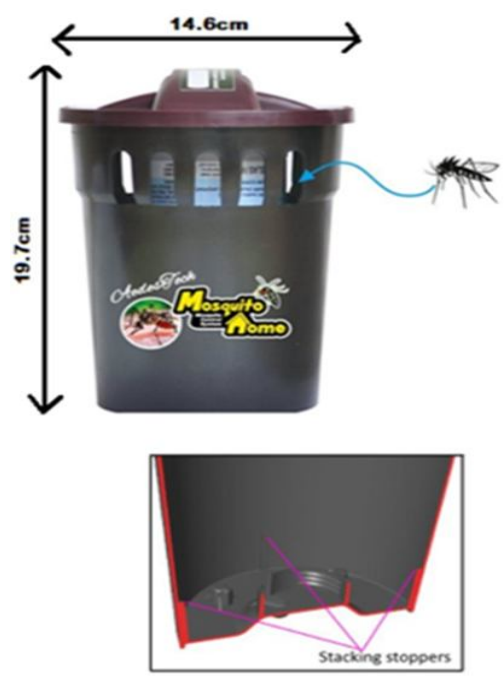

Figure 4: View of exterior skeleton of AMHS

\section{EXPERIMENTATIONS}

\subsection{Trial Site}

The experimental field site is located in an area consisting of 365 residential in a single storey terrace house known as Taman Ria Jaya, Sungai Petani, Kedah (refer to Figure 5). The built-up area of the coverage trial site is approximately 8.0 hectares and consists of 365 units of single storey terrace house. Taman Ria Jaya is an urbanized housing estate, densely populated area in the Sungai Petani, which is dengue hotspot.

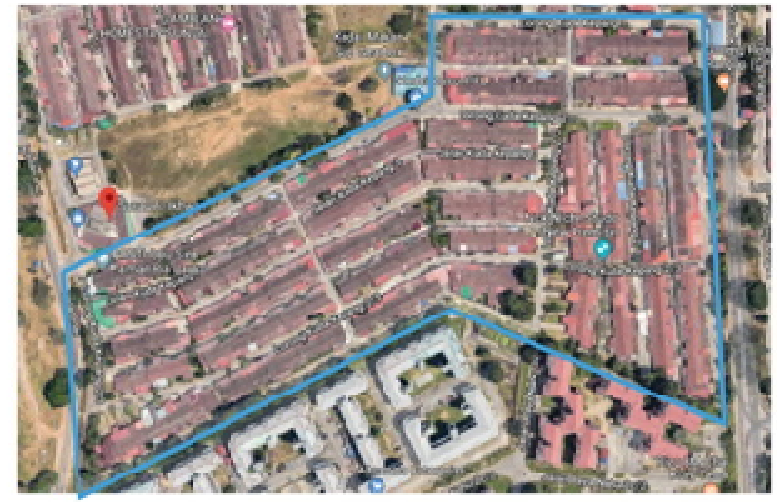

Figure 5: Map of Trial Site in Taman Ria Jaya, Kedah

\subsection{Questionnaires to Local Residents}

The questionnaire survey consists of six simple questions, and we launched a multiple-choice questionnaire to facilitate respondents' responses. The main aim for the questionnaire is to study the public awareness regarding the dengue disease, including dengue vector and the available control tools such as thermal fogging, larviciding and source reduction. The questions are as in Table 2.

Table 2: Questionnaires Set

\begin{tabular}{l|l}
\hline No & \multicolumn{1}{|c}{ Item } \\
\hline 1 & $\begin{array}{l}\text { Do you know which mosquito species is the cause of } \\
\text { Dengue fever? } \\
\text { a. Aedes } \\
\text { b. Culex } \\
\text { c. Anopheles }\end{array}$ \\
\hline 2 & $\begin{array}{l}\text { Did you know that your home is under vector control } \\
\text { study using the AedesTech Mosquito Home System } \\
\text { (AMHS) mosquito trap? } \\
\text { a. Yes } \\
\text { b. No }\end{array}$ \\
\hline 3 & $\begin{array}{l}\text { What is the condition of the mosquito in your home } \\
\text { area after AMHS has been installed for 12 months. } \\
\text { a. Good } \\
\text { b. Reduce } \\
\text { c. Same } \\
\text { d. Not Sure }\end{array}$ \\
\hline 5 & $\begin{array}{l}\text { In your opinion, does this AMHS mosquito trap help } \\
\text { in dengue control in this area? } \\
\text { a. Yes } \\
\text { b. No } \\
\text { c. }\end{array}$ \\
\hline & $\begin{array}{l}\text { If this AMHS mosquito trap program continues, will } \\
\text { a. Yes } \\
\text { b. No }\end{array}$ \\
\hline
\end{tabular}


$6 \quad$ If Ministry of Health continue this Vector Control program in your area, which one of the control methods would you choose?

a. AMHS (Mosquito Trap)

b. Larvaciding

c. Fogging

d. Breeding Site reduction

\section{RESULT AND DISCUSSION}

A total of 119 local residents were participated in this questionnaire study, while 117 of them voluntary to answer the questionnaire, the two resident refuse to answer due to they are foreign worker and do not understand the questions. Fist question is tto find out how the participants know about dengue fever, especially which mosquito species as the main vector. The study found that all participants were aware that Aedes mosquito is the dengue disease vector. When we try to find out whether the local residents aware that their home is under vector control study using the AedesTech Mosquito Home System (AMHS) mosquito trap, the response showed that $99.14 \%$ of the participated local resident aware about it, and only $0.86 \%$ do not know what is going on. With regards to the condition of the mosquito in their home area after AMHS has been installed for 12 months, as high as $86.21 \%$ of the resident feel AMHS is a good system and able to reduce the mosquito population, while $13.79 \%$ feel the mosquito population still remain the same, and $0.85 \%$ not sure about the effectiveness of the AMHS. Figure 6 depicts the percentage of local residents feels and opinion towards the efficacy of mosquito population reduction mechanism. About 90\% agrees on our AMHS approach to reduce the overall mosquito population.

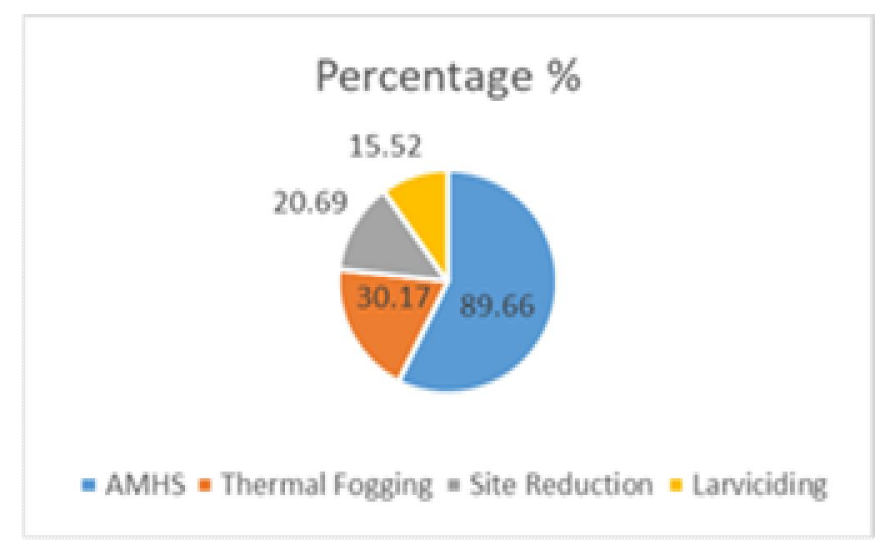

Figure 6: Residents feeling and opinion towards the efficacy of AMHS in mosquito population reduction.

A total of 49 participants provided their comments, opinion or feeling against the uses of AMHS in combating dengue vector in their residential area. There are $89.80 \%$ of the comments were positive and encouraging towards the AMHS, such as residents feel good and satisfied (15 comments or 30.61\%),

AMHS help to reduce mosquito population (22 comments or $44.90 \%$ ), very effective (2 comments or $4.08 \%$ ), AMHS and fogging will help in dengue control, AMHS is a good effort, must keep on, AMHS is the best, AMHS is recommended and AMHS is for the good of all. However, we also found some negative comments against AMHS. It is up to 6.12\% comments are negative against AMHS. The negative nevertheless were it is the same, mosquito population do not reduce (3 comments or $6.12 \%$ ), and other comments (4.08\%), such as due to Pet, do not encourage fogging activity and can only accept water-based fogging.

\section{CONCLUSION AND FUTURE WORKS}

This paper presents the perception of people towards Aedes mosquito and its control mechanism. To illustrate, the target location (Taman Ria Jaya residents) does not indicate any hidden agenda or propaganda, only to get a sample set of respondents for the study. The results indicate that most of the residents prefers the Aedes Mosquito Home System instead of other control mechanism that have been imposed such as fogging, larvaciding or breeding site reductions as a means of its control mechanism. About $89 \%$ respondents prefer the alternative ways of controlling Aedes. This shows that our government Health sector should move towards other Aedes control mechanism in combatting this dangerous mosquito. With what AMHS can offer for its non-pollutant Insecticide Growth Regulator (IGR) and chemical free, the aim is to control starting from the breeding of Aedes eggs instead of fogging towards the adults Aedes mosquito. The pyriproxyfen based formulation is scientifically proven in various researches and it's already formulated in the IGR that comes together in AMHS. Our next future experiments would be to test AMHS in other states of Malaysia with our main locality would be to the state with the current highest dengue cases. With Aedes mosquitoes datasets gained, a specific mobile application is hoped to be developed as defined in [20] just to capture Aedes eggs from the tissue (installed in our AMHS) prior to automatic counting of Aedes eggs before mining between frequent [21] - [22] and infrequent of Aedes data [23] as to complement our Dengue Innovation project.

\section{ACKNOWLEDGEMENT}

We thank all collaborators i.e. UniSZA, UMT, UniKL and One Team Network (OTN) Sdn. Bhd. in matching grant of UniSZA-UMT-UniKL-OTN with project code R0047-R001 as well as all faculty members and grant collaborators for the meaningful comments and suggestions.

\section{REFERENCES}

1. C. Thais, et al. "Differential susceptibilities of Aedes aegypti and Aedes albopictus from the Americas to Zika 
Mustafa Man et al., International Journal of Emerging Trends in Engineering Research, 8(6), June 2020, 2370 - 2374

virus." PLoS neglected tropical diseases 10.3 (2016): e0004543.

https://doi.org/10.1371/journal.pntd.0004543

2. H. Janet, et al. "The Innovative Vector Control Consortium: improved control of mosquito-borne diseases." Trends in parasitology 22.7 (2006): 308-312.

3. B. Anna, et al. "Broad Dengue Neutralization in Mosquitoes Expressing an Engineered Antibody." CELL-D-19-01515 (2019).

4. E. Sudarmilah, M. Thoyib. "Stop Demam Berdarah Dengue (DBD) - Virtual Reality Application for Learning about Dengue Fever." International Journal of Emerging Trends in Engineering Research, 7.11 (2019): 441-448. https://doi.org/10.30534/ijeter/2019/077112019

5. C. M. Seng, N. Jute, "Breeding of Aedes aegypti (L.) and Aedes albopictus (Skuse) in urban housing of Sibu town, Sarawak". Southeast Asian Journal of Tropical Medicine and Public Health. 1994, Sep;25:543.

6. L. Han Lim, I. Mustafakamal, and A. Rohani. "Does transovarial transmission of dengue virus occur in Malaysian Aedes aegypti and Aedes albopictus?." Southeast Asian Journal of Tropical Medicine \& Public Health 28.1 (1997): 230-232.

7. H. L. Lee, "Environmental friendly approaches to mosquito control." Mosquitoes and Mosquito-borne Diseases. Ng, FSP and Yong, HS (eds.). Kuala Lumpur: Academy of Science Malaysia (2000): 223-233.

8. World Health Organization. Dengue haemorrhagic fever: diagnosis, treatment, prevention and control. World Health Organization, 1997.

9. G. George P., and C. E. Taylor. "Genetic and biological influences in the evolution of insecticide resistance." Journal of economic entomology 70.3 (1977): 319-323.

10. C. A. Malcolm, and R. J. Wood. "Location of a gene conferring resistance to knockdown by permethrin and bioresmethrin in adults of the BKPM3 strain of Aedes aegypti." Genetica 59.3 (1982): 233-237.

11. World Health Organization. Test procedures for insecticide resistance monitoring in malaria vectors, bio-efficacy and persistence of insecticides on treated surfaces: report of the WHO informal consultation, Geneva, 28-30 September 1998. No. WHO/CDS/CPC/MAL/98.12. Geneva: World Health Organization, 1998.

12. P. Y. Loh, and H. H. Yap. Laboratory Studies on the Efficacy and Sublethal Effects of an Insect Growth Regulator, Pyriproxyfen (S-31183) Against Aedesaegypti (Linnaeus). 1989.

13. K. Kamimura, and R. Arakawa. "Field evaluation of an insect growth regulator, pyriproxyfen, against Culex pipiens pallens and Culex tritaeniorhynchus." Medical Entomology and Zoology 42.3 (1991): 249-254.

14. C. H. Schaefer, and F. S. Mulligan, "Potential for resistance to pyriproxyfen: a promising new mosquito larvicide." Journal of the American Mosquito Control Association 7.3 (1991): 409-411.
15. T. Okazawa, "Research \& Reports." Journal of the American Mosquito Control Association 7.4 (1991): 604-607.

16. M. Mogi, and J. Mokry. "Distribution of Wyeomyia smithii (Diptera, Culicidae) eggs in pitcher plants in Newfoundland, Canada." Tropical Medicine 22.1 (1980): 1-12.

17. I. Unlu, et al. "Effectiveness of autodissemination stations containing pyriproxyfen in reducing immature Aedes albopictus populations." Parasites \& vectors 10.1 (2017): 1-10

18. AedesTech Mosquito Home. Available: http://www.onedream.com.my/index.php?ws=showprod ucts\&products_id=1010579\&cat=Mosquito-Killer-Repe llent

19. Dengue Tech Challenge 2016. Available: http://www.platcomdiscovery.com/denguetech/winners. aspx

20. M. V. D. Prasad, et al. "Human activity recognition using deep learning." International Journal of Emerging Trends in Engineering Research, 7.11 (2019): 536-541. https://doi.org/10.30534/ijeter/2019/227112019

21. W. A. W. A. Bakar, et al. "Incremental-Eclat Model: An Implementation via Benchmark Case Study." Advances in Machine Learning and Signal Processing. Springer, Cham, 2016. 35-46.

22. M. K. Yusof, and M. Man. "Efficiency of JSON for data retrieval in big data." Indonesian Journal of Electrical Engineering and Computer Science 7.1 (2017): 250-262.

23. J. A. Jusoh, and M. Man. "Modifying iEclat Algorithm for Infrequent Patterns Mining." Advanced Science Letters 24.3 (2018): 1876-1880. https://doi.org/10.1166/asl.2018.11180 